\title{
Swelling of self-adhesive resin cement increases long-term push-out bond strength of fiber post to dentin
}

\author{
Fabrício Mezzomo Collares ${ }^{1}$, Vicente Castelo Branco Leitune ${ }^{1}$, Carolina Rocha Augusto ${ }^{1}$, \\ Patrícia Franken ${ }^{1}$, Susana Maria Werner Samuel ${ }^{1}$
}

${ }^{1}$ Universidade Federal do Rio Grande do Sul - UFRS, School of Dentistry, Dental Materials Laboratory, Porto Alegre, RS, Brazil

\begin{abstract}
Aim: To evaluate the long-term post push-out bond strength to dentin, water sorption, solubility and swelling of conventional and self-adhesive dual-cure resin cements. Methods: Forty-eight bovine roots were prepared for fiber post cementation with RelyX ARC and RelyX U100. According to resin cement and storage time ( $24 \mathrm{~h}$ and 6 months), 4 groups were assessed using the push-out test. Water sorption and solubility were performed according to ISO 4049:2009. The swelling coefficient was obtained using cement disks of each material immersed in distilled water until the swelling equilibrium was reached. The mass of dry and swelled polymer and solvent density were used to calculate the coefficient. Statistical data analysis was performed using Student's t-test for water sorption, solubility and swelling coefficient and the Kruskal-Wallis and Dunn multiple comparison tests for push-out analysis with a significance level of 0.05 . Results: The immediate bond strength was not significantly different between RelyX ARC (3.09 MPa) and RelyX U100 (3.78 MPa) $(p>0.05)$. RelyX U100 showed higher $(p<0.05)$ bond strength after six months of storage (9.60 MPa) than RelyX ARC (6.65 MPa). The water sorption and solubility values were not significantly different $(p>0.05)$ between groups. The swelling coefficient of the RelyX U100 group was significantly higher than that of the RelyX ARC group $(p<0.05)$. Conclusions: RelyX U100 resin cement showed a higher swelling coefficient than RelyX ARC, and the longitudinal push-out bond strength increased after six months. Clinical significance: The clinical longevity of restorative treatment in root-filled teeth is dependent on the long-term properties and behavior of the cement used for post luting. Results of this study suggest that the selfadhesive resin cement may be a reliable alternative.
\end{abstract}

Keywords: resin cements; dentin-bonding agents; solubility; water storage.

\section{Introduction}

Received for publication: September 01, 2015 Accepted: September 29, 2015

Correspondence to: Fabrício Mezzomo Collares Universidade Federal do Rio Grande do Sul Dental Materials Laboratory, School of Dentistry Rua Ramiro Barcelos, 2492 Rio Branco CEP:90035-003 Porto Alegre, RS, Brasil Phone: +55 51 3308-5198 E-mail: fabricio.collares@ufrgs.br
Fiber posts are widely used to restore endodontically treated teeth as an alternative to metal posts and cores. The similarity in the elastic modulus among the fiber post, resin cement and dentin is advantageous for the improved performance of restorative procedures ${ }^{1}$. Moreover, the chemical nature of the posts allows them to be bonded to canal walls with adhesive systems in combination with resin cements.

The choice of a luting agent depends on the clinical situation and on the material's physical, biologic and handling properties. In general, the resin cements are composed of a dimethacrylate-based polymeric matrix, filler particles, pigments 
and chemical substances to start the polymerization reaction. Variation in the content of these components strongly influences the physicochemical properties of the material ${ }^{2}$.

The use of conventional resin cements requires pretreatment of the root surface with an adhesive system ${ }^{3}$ toincrease the bond strength ${ }^{4}$. The adhesion strategy of etchand-rinse adhesive systems involves two or three steps with the successive application of an acid, followed by a primer and an adhesive resin. In self-etch adhesive systems, the etching and priming steps are combined, and in the most recent formulations, etching, priming, and bonding are combined into a single step 5 .

Recently introduced self-adhesive resin cements do not require the pretreatment of the tooth substrate. The adhesive properties of self-adhesive cements are attributed to acidic methacrylate monomers that simultaneously demineralize and infiltrate the tooth substrate, resulting in micromechanical retention ${ }^{6}$. Self-adhesive resin cements present reliable immediate bond strength to dentin ${ }^{1,7,8}$. However, the longevity of bond strength is still a concern for cementation procedures.

Therefore, the purpose of this study was to evaluate the long-term push-out bond strength of post to dentin with conventional and self-adhesive dual-cure resin cements.

\section{Material and methods}

\section{Specimen preparation}

Forty-eight bovine teeth with similar lengths and dimensions were used in this study. Freshly extracted teeth were immediately immersed in distilled water and stored at $4{ }^{\circ} \mathrm{C}$ for no more than 6 months. To be included in this study, the following criteria had to be met: straight roots and root length of at least $15 \mathrm{~mm}$. External debris were removed with a periodontal curette. The crown surfaces of each tooth were sectioned below the cementum-enamel junction, perpendicular to their long axis, using a low speed diamond disc with water coolant.

After endodontic access, the working length was established by the direct method subtracting $1 \mathrm{~mm}$ from the real root length, determined by introducing a $\mathrm{n}^{\circ} 10 \mathrm{~K}$-file (Maillefer-Dentsply, Ballaigues, Switzerland) until the file was visible through the apical foramen. The root canals were prepared with $\mathrm{K}$-files using the step-back technique. The coronal portion of each canal was shaped with size 2 GatesGlidden drills. The root canals were irrigated with $3 \mathrm{~mL}$ distilled water prior to each instrument. After final irrigation, the root canals were dried with absorbent paper points.

\section{Cementation of fiber posts}

The post space of each specimen was enlarged with a $n^{\circ}$ 2 drill from the Exacto post system (Angelus, Londrina, PR, Brazil), $4 \mathrm{~mm}$ before reaching the working length depth. The fiber post was $20 \mathrm{~mm}$ long, $1.4 \mathrm{~mm}$ cervical diameter, and $0.9 \mathrm{~mm}$ apical diameter. To standardize the method, the same operator performed all of the procedures. Following post space preparations, the roots were randomly divided into 4 experimental groups of 12 teeth, according to material and storage time $(\mathrm{n}=12)$.

The resin cements were applied according to the manufacturer's instructions and are shown in Table 1 . The fiber posts were cleaned with $96 \%$ ethanol, and silane was applied with disposable microbrush tips ${ }^{9}$. In the RelyX ARC (3M ESPE) groups, the intracanal dentin was etched with $37 \%$ phosphoric acid for $15 \mathrm{~s}$, rinsed with distilled water for $15 \mathrm{~s}$, and then gently dried with absorbent paper points. The activator (3M ESPE) was applied to the canal with a paper point and gently air-dried followed by application of the primer (Scotch Bond Multi-Purpose Plus, 3M ESPE). The catalyst (3M ESPE) was applied on the root dentin and the post

The cements were inserted only into the root canal ${ }^{10}$ with Accudose (Centix Inc, Shelton, CT, USA) needle tubes and a Centrix syringe (Centrix Inc, Shelton, CT, USA) ${ }^{11}$. The fiber post was inserted and excess cement was removed. Light activation was performed through the cervical portion of the root for $30 \mathrm{~s}$ at the buccal and lingual surfaces for a total of $60 \mathrm{~s}$ of light exposure, with a $5 \mathrm{~mm}$ distance between the source and the root. The resin cement and adhesive were light activated with XL2500 (3M ESPE), with an output intensity of $600 \mathrm{~mW} / \mathrm{cm}^{2}$. The power of the light curing unit was gauged with a radiometer (Model 100, Demetron Research Group, Danbury, CT, USA).

\section{Push-out test}

All the roots in all groups were stored in $37{ }^{\circ} \mathrm{C}$ distilled water for 7 days and then serially sectioned into $0.7 \mathrm{~mm}$ thick slices in a precision cutting machine (Low Speed Saw,

Table 1: Chemical compositions of materials

$\begin{array}{lll}\begin{array}{l}\text { Material } \\ \text { RelyX ARC }\end{array} & \begin{array}{l}\text { Paste A } \\ \text { Paste B }\end{array} & \begin{array}{l}\text { Composition } \\ \text { BISGMA, TEGDMA, silane treated ceramic, silane treated silica, functionalized dimethacrylates polymer, triphenylantimony. }\end{array} \\ \text { RelyX U100 } & \begin{array}{l}\text { Base } \\ \text { Catalyst }\end{array} & \begin{array}{l}\text { Glass powder, methacrylated phosphoric acid esters, triethylene glycol dimethacrylates, silane treated silica, sodium persulfate. } \\ \text { Glass powder, substituted dimethacrylate, silane treated silica, sodium p-toluenesulfinate, calcium hydroxide. }\end{array} \\ \text { Scotch Bond } & & \\ \text { Multi-Purpose Plus } & \begin{array}{l}\text { Primer } \\ \text { Catalyst }\end{array} & \text { HEMA, copolymer of acrylic and itaconic acids, water. } \\ & \text { Activator } & \text { EISGMA, HEMA, benzoyl peroxide, triphenylphosphine, triphenylantimony, hydroquinone. } \\ & \end{array}$


Buehler, Lake Bluff, IL, USA) with constant water cooling. The slices of all roots from each group were stored in $37{ }^{\circ} \mathrm{C}$ distilled water for 24 hours or 6 months before the push-out tests. The cervical and apical diameters of the canal and the thickness of all of the slices were measured with a digital caliper. Each section was marked on its apical side and positioned on a base with a central hole in a universal testing machine (DL2000, EMIC, São José dos Pinhais, PR, Brazil). The push-out test was performed applying a compressive load to the apical side of each slice using a $0.7 \mathrm{~mm}$-diameter cylindrical plunger attached to the upper portion of the testing machine. A crosshead speed of $0.5 \mathrm{~mm} / \mathrm{min}$ was applied until bond failure occurred. To express the bond strength in MPa, the load upon failure was recorded in Newton (N) and divided by the bond area $\left(\mathrm{mm}^{2}\right)^{12}$.

\section{Water Sorption and Solubility}

Water sorption and solubility were determined based on the ISO 4049:2009 standard specification, except for specimen size. Cement disks $(n=5)$ of each material were produced in a polytetrafluoroethylene matrix $(6.0 \mathrm{~mm}$ diameter and 1-mm thick, in order to fit the light output guide of the QTH curing unit). For specimen preparation, the cement was directly dispensed into the mold until it was filled. An acetate strip was placed on top of the cement and covered with a glass slide. The specimens were light activated for $20 \mathrm{~s}$, removed from the mold and the opposite surface received additional light activation for $20 \mathrm{~s}$.

Specimens were placed in a desiccator containing silica gel at $37{ }^{\circ} \mathrm{C}$. The disks were repeatedly weighed after $24-\mathrm{h}$ intervals on an analytical scale until a constant mass (m1) was obtained (i.e., until the mass loss of each specimen was not more than $0.1 \mathrm{mg}$ in any $24-\mathrm{h}$ period). The diameter and thickness of each specimen were measured with a digital caliper to calculate the volume (V) of each disk (in $\mathrm{mm}^{3}$ ). Thereafter, the specimens were stored in sealed glass vials with $10 \mathrm{~mL}$ distilled water at $37{ }^{\circ} \mathrm{C}$ for 7 days. After seven days, the disks were weighed after being washed under running water and gently wiped with an absorbent paper to obtain the mass measure $(\mathrm{m} 2)$ and then returned to the desiccator. Next, the specimens were weighed until a constant mass (m3) was obtained (as described above). Water sorption (WS) and solubility (SL) were calculated in micrograms per cubic millimeter ${ }^{13}$.

\section{Swelling coefficient}

Swelling coefficient measurements were performed gravimetrically. Cement samples $(n=3)$ of each material were produced in a polytetrafluoroethylene matrix $(2 \times 2 \times 12$ $\mathrm{mm})$. Next, the samples were immersed in distilled water at $37{ }^{\circ} \mathrm{C}$ until swelling equilibrium was reached. Then, the samples were removed, the excess solution deposited on the film surface was quickly removed with blotting paper and the samples were weighed.

The values of the swelling coefficients $(\alpha)$ of all materials were calculated using the following equation:

$$
\alpha=\left(\left(M_{\text {eq }}-M_{0}\right) / M_{0}\right) \times 1 / d_{s}
$$

Where $\mathrm{M}_{\mathrm{eq}}$ is the mass of the sample (polymer+solvent) after equilibrium, $M_{0}$ the mass of the polymer, and $d_{s}$ is the density of the solvent ${ }^{14}$.

\section{Statistical analysis}

Statistical analysis was performed using SigmaStat (version 4, Ashburn, GA, USA). The normality of the results was tested using the Kolmogorov-Smirnov test. The used statistical tests were Student's t-test for water sorption, solubility and swelling coefficient and the Kruskal-Wallis and Dunn multiple comparison tests for push-out analysis, all at a significance level of 0.05 .

\section{Results}

The results of the bond strength analysis are presented in Figure 1. The RelyX ARC group exhibited $3.09( \pm 1.72)$ $\mathrm{MPa}$ at $24 \mathrm{~h}$ and $5.65( \pm 5.77) \mathrm{MPa}$ at 6 months $(\mathrm{p}>0.05)$. The RelyX U100 group presented $3.78( \pm 1.84) \mathrm{MPa}$ and $9.60( \pm 7.65) \mathrm{MPa}$ at $24 \mathrm{~h}$ and 6 months $(\mathrm{p}<0.05)$, respectively.

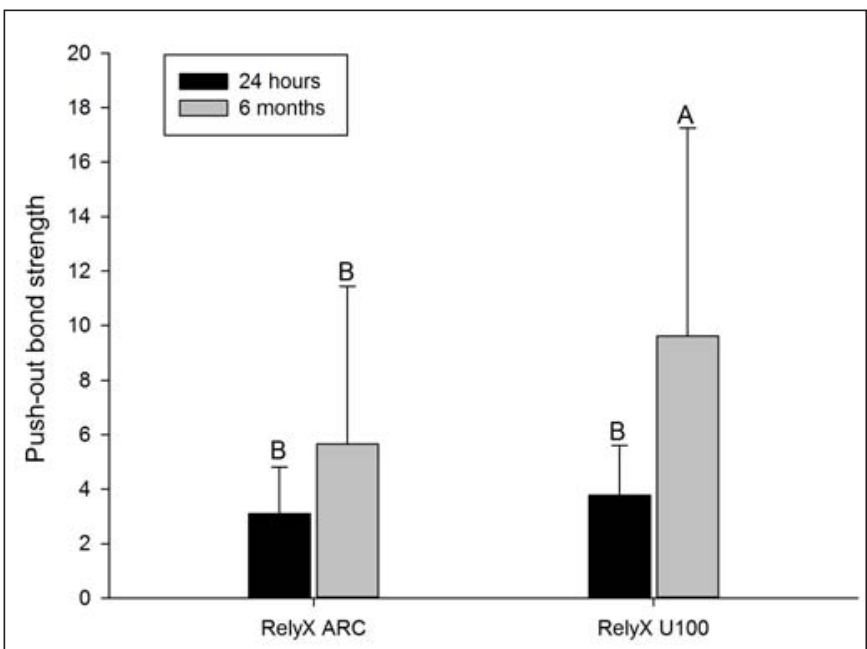

Fig. 1: Bond strength values as a function of evaluation period and cement type. Different letters represents statistically significant difference among groups $(p<0.05)$.

Water sorption and solubility showed no statistical differences $(p>0.05)$ between cements. The swelling coefficient of the RelyX U100 group $(0.027 \mathrm{mLg})$ was significantly higher than that of the RelyX ARC group $(0.011$ $\mathrm{mLg})(\mathrm{p}<0.05)$. The means and standard deviations are shown in Table 2.

Table 2: Mean and standard deviation ( \pm SD) of water sorption (WS), solubility (SL) and swelling coefficient $(\alpha)$ of the resin cement

\begin{tabular}{llll}
\hline Group & wS $\left(\mu \mathrm{g} / \mathrm{cm}^{3}\right)$ & $\mathrm{SL}\left(\mu \mathrm{g} / \mathrm{cm}^{3}\right)$ & $\boldsymbol{\alpha}(\mathrm{mLg})$ \\
RelyX ARC & $19.27( \pm 1.39)$ & $2.19( \pm 0.45)$ & $0.011( \pm 0.00006)$ \\
RelyX U100 & $19.94( \pm 2.98)$ & $0.86( \pm 1.48)$ & $0.027( \pm 0.00172)$ \\
$p$ & 0.66 & 0.09 & 0.000 \\
\hline
\end{tabular}




\section{Discussion}

The clinical longevity of restorative treatment in rootfilled teeth relies on the properties of the used cement ${ }^{3}$. Water movement from the intra-radicular dentin through the hybrid layer is one of the reasons for cement/dentin interface degradation over time ${ }^{15}$. In this study, the tested resin cements showed similar water sorption, solubility and immediate pushout bond strength. Nevertheless, RelyX U100 demonstrated higher swelling coefficients and longitudinal push-out bond strength values than RelyX ARC.

Water sorption of polymers could lead to degradation ${ }^{15}$. Furthermore, the polymer could undergo hygroscopic expansion ${ }^{2,16}$ due to the chemistry of monomers and polymerization linkages ${ }^{17}$. Monomers like HEMA, Bis-GMA and TEGDMA are heteroatom structures composed of carbon and oxygen ${ }^{15}$ revealing the presence of hydrolytically susceptible ester groups ${ }^{18}$. Water sorption of resin composites depends on the degree of conversion of the polymer, the polar interaction, the particle size and morphology of the filler, and the surface area exposed to water ${ }^{17}$. In this study, all specimens presented water sorption after seven days of storage.

The swelling coefficient was calculated based on the mass of the polymer before and after immersion, when the polymer shows a constant swelling mass. In this study, the resin cements only presented a stable mass after 29-day immersion. RelyX U100 presented higher swelling coefficient than RelyX ARC. Self-adhesive resin cement contains acidic monomers (e.g., carboxylated or phosphate-derivatized methacrylates) in its composition, which have polar structures, leading to increased water sorption ${ }^{19}$.

Retention of fiber posts in roots depends on the bond strength between post material and a resin luting agent, bond strength between post space dentin and resin luting agent ${ }^{1}$. Despite the difference in the mechanism of adhesion of both tested materials, immediate push-out bond strength presented no difference in this study, corroborating other studies ${ }^{12,20-24}$. Although resin cements present reliable immediate results, the longevity of the bond strength should be evaluated. Adhesive interfaces are prone to degradation over time, leading to a decrease in bond strength. One could think that 6 months of water storage could decrease the push-out bond strength of resin cements. However, in this study, six months of storage significantly increased the bond strength values for the RelyX U100 group.

According to a systematic review there is a $3.81 \mathrm{MPa}$ increase of resistance to dislodgement for bovine teeth when compared to human teeth ${ }^{25}$. The increase in value is proportional to the used type of teeth. In the present study, bovine teeth were used in all groups.

Considering the water sorption value $\left(19.94 \mu \mathrm{g} / \mathrm{cm}^{3}\right)$ and low solubility $\left(0.86 \mu \mathrm{g} / \mathrm{cm}^{3}\right)$, RelyX U100 presented hygroscopic expansion leading to material swelling. The hygroscopic behavior of materials is strongly influenced by filler composition ${ }^{17}$. The self-adhesive resin cement used in this study contains fluoraluminosilicate glass powder, which exhibits hygroscopic expansion ${ }^{26}$. Glass-ionomer and resin- modified glass-ionomer luting cements presented delayed hygroscopic expansion increasing fiber post retention ${ }^{27}$. The hygroscopic expansion could explain the increased longterm bond strength values showed in this study. The RelyX ARC group exhibited lower push-out bond strength values after six months of storage, suggesting that a concurrent solubility $\left(2.19 \mu \mathrm{g} / \mathrm{cm}^{3}\right)$ process occurred during the water sorption stage ${ }^{28}$. The sorption and solubility features of resin cements have been studied ${ }^{29}$, and the structural characteristics of polymers are essential to determine the extent to which polymers are affected by an aqueous environment ${ }^{17}$. Other parameters, such as the cross-linking density of the polymeric network ${ }^{29}$, the amount of monomers ${ }^{30}$ and polarity of functional groups may affect the cement behavior. The results presented by RelyX ARC are in agreement with the current literature ${ }^{31-32}$.

Despite the materials' degradation over time, the selfadhesive resin cement showed higher bond strength after six months, presenting a high swelling coefficient and low solubility. Considering that the leachability of dental polymers is a biological concern, polymers with low release of components are required.

\section{Acknowledgements}

The authors would like to express their thanks to CAPES and FAPEAM for the financial support.

\section{References}

1. Das AK, Muddugangadhar BC, Amarnath GS, Garg A, Kumar U, Rao TR. Comparative evaluation of push out bond strength of a fiber post system using four different resin cements: an in vitro study. J Int Oral Health. 2015; 7: 62-7.

2. Braga RR, Cesar PF, Gonzaga CC. Mechanical properties of resin cements with different activation modes. J Oral Rehabil. 2002; 29: 257-62.

3. Silva RA, Coutinho M, Cardozo PI, Silva LA, Zorzatto JR. Conventional dual-cure versus self-adhesive resin cements in dentin bond integrity. J Appl Oral Sci. 2011; 19: 355-62.

4. Pashley DH, Tay FR, Breschi L, Tjaderhane L, Carvalho RM, Carrilho M, et al. State of the art etch-and-rinse adhesives. Dent Mater. 2011; 27:1-16.

5. Vaidyanathan TK, Vaidyanathan J. Recent advances in the theory and mechanism of adhesive resin bonding to dentin: a critical review. J Biomed Mater Res B Appl Biomater. 2009; 88: 558-78.

6. Moraes RR, Boscato N, Jardim PS, Schneider LF. Dual and self-curing potential of self-adhesive resin cements as thin films. Oper Dent. 2011; 36: 635-42.

7. Peumans M, Voet M, De Munck J, Van Landuyt K, Van Ende A, Van Meerbeek B. Four-year clinical evaluation of a self-adhesive luting agent for ceramic inlays. Clin Oral Investig. 2013; 17: 739-50.

8. Frassetto A, Navarra CO, Marchesi G, Turco G, Di Lenarda R, Breschi $L$, et al. Kinetics of polymerization and contraction stress development in self-adhesive resin cements. Dent Mater. 2012; 28: 1032-9.

9. Li R, Zhou H, Wei W, Wang C, Sun YC, Gao P. Effects of mechanical and chemical pretreatments of zirconia or fiber posts on resin cement bonding. PLoS One. 2015; 10: 1-12.

10. Skupien JA, Sarkis-Onofre R, Cenci MS, de Moraes RR, Pereira-Cenci T. Asystematic review of factors associated with the retention of glass fiber posts. Braz Oral Res. 2015; 29: 1-8. 
11. Souza AC, Gonçalves F de C, Anami LC, Melo RM, Bottino MA, Valandro LF. Influence of insertion techniques for resin cement and mechanical cycling on the bond strength between fiber posts and root dentin. J Adhes Dent. 2015; 17: 175-80.

12. Kahnamouei MA, Mohammadi N, Navimipour EJ, Shakerifar M. Pushout bond strength of quartz fibre posts to root canal dentin using total-etch and self-adhesive resin cements. Med Oral Patol Oral Cir Bucal. 2012; 17: e337-44.

13. Collares FM, Ogliari FA, Zanchi CH, Petzhold CL, Piva E, Samuel SM. Influence of 2-hydroxyethyl methacrylate concentration on polymer network of adhesive resin. J Adhes Dent. 2011; 13: 125-9.

14. Neumann MG, Schmitt CC, Catalina F, Goi BE. The relation between the polymerization rates and swelling coefficients for copolymers obtained by photoinitiation. Polymer Testing. 2007; 26: 189-94.

15. Ferracane JL. Hygroscopic and hydrolytic effects in dental polymer networks. Dent Mater. 2006; 22: 211-22.

16. Zhu S, Platt J. Curing efficiency of three different curing modes at different distances for four composites. Oper Dent. 2011; 36: 362-71.

17. Malacarne J, Carvalho RM, de Goes MF, Svizero N, Pashley DH, Tay FR, et al. Water sorption/solubility of dental adhesive resins. Dent Mater. 2006; 22: 973-80.

18. Collares FM, Leitune VCB, Portella FF, Ogliari FA, Samuel SMW. Longterm bond strength, degree of conversion and resistance to degradation of a HEMA-free model adhesive. Braz J Oral Sci. 2014; 13: 261-5.

19. Nakaoki Y, Nikaido T, Pereira PN, Inokoshi S, Tagami J. Dimensional changes of demineralized dentin treated with HEMA primers. Dent Mater. 2000; 16: 441-6.

20. Calixto LR, Bandeca MC, Clavijo V, Andrade MF, Vaz LG, Campos EA. Effect of resin cement system and root region on the push-out bond strength of a translucent fiber post. Oper Dent. 2012; 37: 80-6.

21. Amaral M, Rippe MP, Bergoli CD, Monaco C, Valandro LF. Multi-step adhesive cementation versus one-step adhesive cementation: push-out bond strength between fiber post and root dentin before and after mechanical cycling. Gen Dent. 2011; 59: e185-91.

22. Bergoli $C D$, Amaral M, Druck CC, Valandro LF. Evaluation of four cementation strategies on the push-out bond strength between fiber post and root dentin. Gen Dent. 2011; 59: 498-502.

23. Amaral M, Rippe MP, Konzen M, Valandro LF. Adhesion between fiber post and root dentin: evaluation of post surface conditioning for bond strength improvement. Minerva Stomatol. 2011; 60: 279-87.

24. Gomes GM, Gomes OM, Reis A, Gomes JC, Loguercio AD, Calixto AL. Regional bond strengths to root canal dentin of fiber posts luted with three cementation systems. Braz Dent J. 2011; 22: 460-7.

25. Collares FM, Portella FF, Rodrigues SB, Celeste RK, Leitune VC, Samuel $\mathrm{SM}$. The influence of methodological variables on the push-out resistance to dislodgement of root filling materials: a meta-regression analysis. Int Endod J. 2015; doi: 10.1111/iej.12539.

26. 26- Yiu CK, Tay FR, King NM, Pashley DH, Carvalho RM, Carrilho MR. Interaction of resin-modified glass-ionomer cements with moist dentine. JDent. 2004; 32: 521-30.

27. Cury AH, Goracci C, de Lima Navarro MF, Carvalho RM, Sadek FT, Tay FR, et al. Effect of hygroscopic expansion on the push-out resistance of glass ionomer-based cements used for the luting of glass fiber posts. J Endod. 2006; 32: 537-40.

28. Wei YJ, Silikas N, Zhang ZT, Watts DC. Diffusion and concurrent solubility of self-adhering and new resin-matrix composites during water sorption/ desorption cycles. Dent Mater. 2011; 27: 197-205.

29. Attar N, Tam LE, McComb D. Mechanical and physical properties of contemporary dental luting agents. J Prosthet Dent. 2003; 89: 127-34.

30. Marghalani HY. Sorption and solubility characteristics of self-adhesive resin cements. Dent Mater. 2012; 28: e187-98.

31. Leme AA, Coutinho M, Insaurralde AF, Scaffa PM, da Silva LM. The influence of time and cement type on push-out bond strength of fiber posts to root dentin. Oper Dent. 2011; 36: 643-8.
32. Pereira JR, da Rosa RA, Só MV, Afonso D, Kuga MC, Honorio HM et al. Push out bond strength of fiber post to root dentin using glass ionomer and resin modified glass ionomer cements. J Appl Oral Sci. 2014 ;22: 390-6. 